Federal Reserve Bank of Minneapolis

Research Department Staff Report 260

April 1999

\title{
Money and Interest Rates With Endogenously Segmented Markets
}

\author{
Fernando Alvarez* \\ University of Chicago \\ Universidad Torcuato Di Tella \\ and National Bureau of Economic Research
}

\author{
Andrew Atkeson* \\ University of Minnesota \\ Federal Reserve Bank of Minneapolis \\ and National Bureau of Economic Research \\ Patrick J. Kehoe* \\ University of Pennsylvania \\ Federal Reserve Bank of Minneapolis \\ and National Bureau of Economic Research
}

\begin{abstract}
This paper analyses the effects of open market operations on interest rates in a model in which agents must pay a fixed cost to exchange assets and cash. Asset markets are endogenously segmented in that some agents choose to pay the fixed cost and some do not. When the fixed cost is zero, the model reduces to the standard one in which persistent money injections increase nominal interest rates, flatten the yield curve, and lead to a downward-sloping yield curve on average. In contrast, if markets are sufficiently segmented, then persistent money injections decrease interest rates, steepen or even twist the yield curve, and lead to an upwardsloping yield curve on average.
\end{abstract}

*We thank Robert E. Lucas, Jr., Dean Corbae, and Stanley Zin for their comments and acknowledge support from the National Science Foundation. The views expressed herein are those of the authors and not necessarily those of the Federal Reserve Bank of Minneapolis or the Federal Reserve System. 
We study the connection between money and interest rates in a model with endogenously segmented markets. In the model, agents must pay a fixed cost to transfer money between the asset market and the goods market. In equilibrium, in any period, some agents choose to pay the fixed cost and thus, at the margin, freely trade bonds and money. Other agents choose not to pay the fixed cost and, hence, do not make such trades. Thus, the asset market is segmented in the sense that when the government injects money through an open market operation, only a fraction of the agents in the economy are on the other side of the transaction. We use this model to study the response of interest rates to a money growth shock and the implications of monetary policy for the average term structure of interest rates.

We focus on two features of money and interest rates that have been discussed extensively in the literature. One is that at least since Friedman (1968), there has been a belief that open market operations have liquidity effects: money injections lead initially to a decline in short-term nominal interest rates. These liquidity effects are thought to decay over time, with short-term rates eventually returning to normal levels or even rising. Accordingly, money injections are thought to steepen the yield curve, lowering long-term rates less than short-term rates or even raising long-term rates. The other feature we focus on is the widely documented fact that the yield curve is upward-sloping on average. (See, for example, Campbell, Lo, and MacKinlay 1997.)

Our model can produce both of these features while the standard model cannot. In the standard model without segmented markets, persistent money injections increase interest rates of all maturities, flatten the yield curve, and lead to a downward-sloping yield curve on average. In contrast, in our model, if markets are sufficiently segmented, there are liquidity effects: persistent money injections lower short-term nominal interest rates, steepen or even 
twist the yield curve, and lead to an upward-sloping yield curve on average.

The basic idea that money injections have liquidity effects because only a fraction of agents participate in any given open market operation is familiar from Grossman and Weiss (1983) and Rotemberg (1984). Their models are cash-in-advance models in which half the agents can transfer money between the asset market and the goods market in even periods and half can do so in odd periods. In these models, markets are segmented in the sense that when the government injects money, only those agents currently in contact with the asset market absorb the new money. In addition to these trading frictions, the Grossman-WeissRotemberg models exogenously limit asset trade to uncontingent bonds. Because of that market incompleteness, in addition to the pure liquidity effects from the trading frictions, these models have complicated wealth effects which effectively limit these studies to onetime unanticipated shocks in deterministic environments.

The subsequent literature, initiated by Lucas (1990), organizes agents in coalitions as a simple device to abstract from wealth effects. In a coalition, agents pool their resources and choose consumption subject to a single budget constraint for the coalition as a whole, subject to restrictions on the trading technology. Given the trading technology, then, markets are complete. Thus, monetary injections have real effects only because of the trading frictions and not because of additional exogenous market incompleteness.

The models in this literature are distinguished by types of trading frictions. In Lucas (1990); Fuerst (1992); Chari, Christiano, and Eichenbaum (1995); and Christiano and Eichenbaum (1995), the trading friction is that the coalition must divide its cash each period into a portion to be used to purchase goods and a portion to be traded for bonds in the asset market or used by firms in production, before the size of the current open market operation 
is announced. Unfortunately, in simple versions of these models, liquidity effects last only one period. ${ }^{1}$ Alvarez and Atkeson (1997) use an alternative type of friction that permits agents to be in contact with asset markets only at exogenous times. This model can generate persistent liquidity effects, but only when velocity is extremely low.

Here we use a different friction: our trading technology requires that agents must pay a fixed cost to transfer money between the goods market and the asset market. In addition, trade in the goods market is subject to a cash-in-advance constraint. Here, as in Lucas (1990), given the trading technology, markets are complete. In each period, it is optimal for agents to follow a type of cutoff rule. Agents with high real balances pay the fixed cost to transfer cash to the asset market, while those with low real balances pay the fixed cost to obtain cash from the asset market. Agents with medium real balances do not pay the fixed cost and simply consume their current cash holdings. The assumption of complete markets makes the model tractable, because this assumption implies that all agents follow the same cutoff rule. We refer to the agents who pay the fixed costs as traders, and we refer to those who do not as nontraders.

The fixed cost is the key difference between our model and a standard cash-in-advance model. If the fixed cost is zero, then all agents are traders, and our model reduces to a standard model. Then money injections have no effect on real interest rates and thus affect nominal interest rates only through their effect on expected inflation. Since persistent money growth shocks raise expectations of inflation, these shocks raise nominal interest rates. If the

\footnotetext{
${ }^{1}$ In a variant on their basic model, Chari, Christiano, and Eichenbaum (1995) and Christiano and Eichenbaum (1995) show how introducing costs of portfolio adjustment can lead to longer lasting liquidity effects. Evans and Marshall (1997) use this model to analyze the response of interest rates of different maturities to monetary shocks.
} 
fixed cost is positive, however, when the government injects money by buying bonds, only the fraction of agents who are traders are on the other side of the market. Money injections fall disproportionately on these agents, who thus increase their current consumption, decrease their current marginal utility, and, hence, decrease real interest rates. We refer to this additional effect of money injections on interest rates as the segmentation effect. If this segmentation effect outweighs the standard expected inflation effect, then a persistent increase in money growth in the model has a persistent liquidity effect on interest rates.

Our model's implications for the average yield curve also differ from those of the standard model. In the standard model, the fixed cost is zero and money growth shocks have only standard expected inflation effects which, by themselves, tend to make the average nominal yield curve downward-sloping. In contrast, in our model, when the fixed cost is positive and money shocks are mean-reverting, the consumption of traders is mean-reverting because of the segmentation effect. Generally, if the consumption of agents in financial markets is mean-reverting, then the yield curve for real interest rates is upward-sloping (Campbell 1986; Backus, Gregory, and Zin 1989, 1998; and Labadie 1994). If this segmentation effect outweighs the standard expected inflation effect, then the nominal yield curve is upward-sloping.

Finally, our model is related to the Baumol (1952) and Tobin (1956) models in which agents pay a fixed cost each time they trade bonds and money. Jovanovic (1982), Romer (1986), and Chatterjee and Corbae (1992) develop general equilibrium versions of these models and use them to study how different constant inflation rates affect the steady state. In contrast to all of those studies, however, this one examines the dynamic response of interest rates to money growth shocks. 


\section{The Economy}

Consider a cash-in-advance economy with an infinite number of periods $t=0,1,2, \ldots$, a government, and a continuum of agents of measure 1 . Trade in this economy occurs in two separate locations: an asset market and a goods market. In the asset market, agents trade cash and bonds which promise delivery of cash in the asset market in the next period, and the government introduces cash via open market operations. In the goods market, agents use cash to buy goods subject to a cash-in-advance constraint, and agents sell their endowments for cash. Agents face a real fixed cost of $\gamma$ for each transfer of cash between the asset market and the goods market.

This economy has two sources of uncertainty: idiosyncratic shocks to agents' endowments and shocks to money growth. Each period $t \geq 1$, each agent in the economy has an endowment $y$ which is independent and identically distributed with distribution $F$ which has density $f$. Let $Y=\int y f(y) d y$ be the constant aggregate endowment. In period 1, agents also have $y_{0} / \mu_{1}$ real balances in the goods market, where $y_{0}$ also has distribution $F$ and $\mu_{1}$ is the money growth shock at the beginning of period 1 . In period 0 , agents have $\bar{B}$ units of government debt, which is a claim on $\bar{B}$ dollars in the asset market in period 0. Let $y^{t}=\left(y_{0}, y_{1}, y_{2}, \ldots, y_{t}\right)$ denote a typical history of individual shocks up through period $t$ and $f\left(y^{t}\right)=f\left(y_{0}\right) f\left(y_{1}\right) \ldots f\left(y_{t}\right)$ the probability density over such histories. Let $M_{t}$ denote the aggregate stock of money in period $t$, and let $\mu_{t}=M_{t} / M_{t-1}$ denote the growth rate of that money supply. Let $\mu^{t}=\left(\mu_{1}, \ldots, \mu_{t}\right)$ denote the history of money growth shocks up through period $t$, and let $g\left(\mu^{t}\right)$ denote the probability density over such histories. Let $g\left(\mu_{t} \mid \mu^{t-1}\right)$ denote the conditional density of $\mu_{t}$ given $\mu^{t-1}$.

The timing within each period $t \geq 1$ is as follows. At the beginning of the period, 
money growth $\mu_{t}$ is realized, bonds and cash are exchanged in the asset market, and agents pay cash in the asset market to a firm that transfers cash between the asset and goods markets. Agents then use real balances in the goods market to purchase consumption before learning the realization of their endowment, and then they sell their endowment $y_{t}$ for cash. In period 0 , there is no trade in goods, and agents simply trade bonds.

The government issues one-period bonds contingent on the aggregate state $\mu^{t}$. In period $t$, given state $\mu^{t}$, the government pays off outstanding bonds $B\left(\mu^{t}\right)$ in cash and issues claims to cash in the next asset market of the form $B\left(\mu^{t}, \mu_{t+1}\right)$ at prices $q\left(\mu^{t}, \mu_{t+1}\right)$. The government budget constraint in period $t \geq 1$, given state $\mu^{t}$, is

$$
B\left(\mu^{t}\right)=M\left(\mu^{t}\right)\left(1-\frac{1}{\mu_{t}}\right)+\int_{\mu_{t+1}} q\left(\mu^{t}, \mu_{t+1}\right) B\left(\mu^{t}, \mu_{t+1}\right) d \mu_{t+1} .
$$

In period 0 , this constraint is $\bar{B}=\int_{\mu_{1}} q\left(\mu_{1}\right) B\left(\mu_{1}\right) d \mu_{1}$.

In the asset market in each period and state, agents trade a set of one-period bonds that have payoffs next period which are contingent on both the aggregate event $\mu_{t+1}$ and their endowment realization $y_{t}$. An agent in $t$ with aggregate state $\mu^{t}$, and individual shock history $y^{t-1}$ purchases $B\left(\mu^{t}, \mu_{t+1}, y^{t-1}, y_{t}\right)$ claims to cash that pay off in the next period contingent on the aggregate shock $\mu_{t+1}$ and the agent's endowment shock $y_{t}$. We let $q\left(\mu^{t}, \mu_{t+1}, y_{t}\right)$ be the price of such a bond that pays one dollar in the asset market in period $t+1$ contingent on the relevant events. Because individual endowments are i.i.d. across individuals, we assume that these bond prices do not depend on the name of the individual.

Instead of letting each agent trade in all possible claims contingent on other agents' endowments, we suppose that each agent trades only in claims contingent on the agent's own endowment with some intermediary. This intermediary buys government bonds and trades in 
the agent-specific contingent claims. This latter approach is much less cumbersome than the former and yields the same outcomes. Specifically, the intermediary buys government bonds $B\left(\mu^{t}\right)$ and sells agent-specific claims of the form $B\left(\mu^{t}, y^{t-1}\right)$ to all the agents to maximize profits

$$
\begin{aligned}
& \int_{\mu_{t+1}} \int_{y^{t}} q\left(\mu^{t}, \mu_{t+1}, y_{t}\right) B\left(\mu^{t}, \mu_{t+1}, y^{t-1}, y_{t}\right) f\left(y^{t-1}\right) d y^{t} d \mu_{t+1}- \\
& \int_{\mu_{t+1}} q\left(\mu^{t}, \mu_{t+1}\right) B\left(\mu^{t}, \mu_{t+1}\right) d \mu_{t+1}
\end{aligned}
$$

subject to the constraint

$$
B\left(\mu^{t+1}\right)=\int_{y^{t}} B\left(\mu^{t+1}, y^{t}\right) f\left(y^{t}\right) d y^{t}
$$

Lack of arbitrage requires that the price functions $q\left(\mu^{t}, y_{t-1}\right)$ and $q\left(\mu^{t}\right)$ satisfy $q\left(\mu^{t}, y_{t-1}\right)=$ $q\left(\mu^{t}\right) f\left(y_{t-1}\right)$. Notice that with these price functions, the profits of the intermediary are zero.

Consider now the problem of an individual agent. Let $P\left(\mu^{t}\right)$ denote the price level in the goods market in period $t$. In the goods market, in each period $t \geq 1$, agents start with real balances $m\left(\mu^{t}, y^{t-1}\right)$. They then choose transfers of real balances between the goods market and the asset market $x\left(\mu^{t}, y^{t-1}\right)$, an indicator variable $z\left(\mu^{t}, y^{t-1}\right)$ equal to zero if these transfers are zero and one if they are not, consumption $c\left(\mu^{t}, y^{t-1}\right)$, and unspent real balances to carry over from goods shopping $a\left(\mu^{t}, y^{t-1}\right)$ subject to the cash flow constraints

$$
\begin{aligned}
& a\left(\mu^{t}, y^{t-1}\right)=m\left(\mu^{t}, y^{t-1}\right)+x\left(\mu^{t}, y^{t-1}\right) z\left(\mu^{t}, y^{t-1}\right)-c\left(\mu^{t}, y^{t-1}\right) \\
& m\left(\mu^{t+1}, y^{t}\right)=\frac{P\left(\mu^{t}\right)}{P\left(\mu^{t+1}\right)}\left[y_{t}+a\left(\mu^{t}, y^{t-1}\right)\right]
\end{aligned}
$$

and the cash-in-advance constraints

$$
a\left(\mu^{t}, y^{t-1}\right) \geq 0
$$


where in (3) when $t=1$, the term $m\left(\mu^{t}, y^{t-1}\right)$ is given by $y_{0} / \mu_{1}$.

In the asset market, each period agents start with cash payments $B\left(\mu^{t}, y^{t-1}\right)$ on their bonds and $N\left(\mu^{t-1}, y^{t-2}\right)$ held over as cash from the previous asset market. They purchase new bonds, make cash transfers to the goods market, and hold $N\left(\mu^{t}, y^{t-1}\right)$ over in cash to the next asset market subject to the sequence of budget constraints for $t \geq 1$ :

$$
\begin{aligned}
B\left(\mu^{t}, y^{t-1}\right)= & \int_{\mu_{t+1}} \int_{y_{t}} q\left(\mu^{t}, \mu_{t+1}\right) B\left(\mu^{t}, \mu_{t+1}, y^{t-1}, y_{t}\right) f\left(y_{t}\right) d \mu_{t+1} d y_{t}+ \\
& N\left(\mu^{t}, y^{t-1}\right)-N\left(\mu^{t-1}, y^{t-2}\right)+P\left(\mu^{t}\right)\left[x\left(\mu^{t}, y^{t-1}\right)+\gamma\right] z\left(\mu^{t}, y^{t-1}\right),
\end{aligned}
$$

with $N\left(\mu^{t}, y^{t-1}\right) \geq 0$ and $N\left(\mu^{t-1}, y^{t-2}\right)=N_{0}$ in period $t=1$. In period $t=0$, this asset market constraint is $\bar{B}=\int_{\mu_{1}} \int_{y_{0}} q\left(\mu_{1}\right) B\left(\mu_{1}, y_{0}\right) f\left(y_{0}\right) d y_{0} d \mu_{1}+N_{0}$. Assume that both consumption and real bond holdings $B\left(\mu^{t}, y^{t-1}\right) / P\left(\mu^{t}\right)$ are uniformly bounded by some large constants. Notice that $N\left(\mu^{t}, y^{t-1}\right)$ is cash that agents hold over in the asset market while $P\left(\mu^{t}\right) a\left(\mu^{t}, y^{t-1}\right)$ is cash that agents hold over in the goods market.

The problem of consumers is to maximize utility

$$
\sum_{t=0}^{\infty} \beta^{t} \iint U\left(c\left(\mu^{t}, y^{t-1}\right)\right) g\left(\mu^{t}\right) f\left(y^{t-1}\right) d \mu^{t} d y^{t-1}
$$

subject to the constraints (3)-(6).

The economy has a firm that transfers cash between the asset market and the goods market. Since each transfer of cash consumes $\gamma$ units of goods, the total goods cost of carrying out all transfers at $t$ is $\gamma \int z\left(\mu^{t}, y^{t-1}\right) f\left(y^{t-1}\right) d y^{t-1}$. The firm purchases these goods in the goods market with cash obtained from consumers in that period's asset market.

The resource constraint is given by

$$
\int\left[c\left(\mu^{t}, y^{t-1}\right)+\gamma z\left(\mu^{t}, y^{t-1}\right)\right] f\left(y^{t-1}\right) d y^{t-1}=Y
$$


for all $t, \mu^{t}$, and the money market clearing condition is given by

$$
\begin{aligned}
M\left(\mu^{t}\right) / P\left(\mu^{t}\right)= & N\left(\mu^{t}\right)-N\left(\mu^{t-1}\right)+ \\
& \int\left(m\left(\mu^{t}, y^{t-1}\right)+\left[x\left(\mu^{t}, y^{t-1}\right)+\gamma\right] z\left(\mu^{t}, y^{t-1}\right)\right) f\left(y^{t-1}\right) d y^{t-1}
\end{aligned}
$$

for all $\mu^{t}$ with $N\left(\mu^{t}\right)=\int_{y^{t-1}} N\left(\mu^{t}, y^{t-1}\right) f\left(y^{t-1}\right) d y^{t-1}$. Let $c$ denote the sequence of functions $c\left(\mu^{t}, y^{t-1}\right)$, and use similar notation for other variables.

Here, an equilibrium is a collection of bond and goods prices $q$ and $P$, together with bond holdings $B$ and an allocation $c, x, z, a, m$ such that the bond holdings and the allocation solve the agent's utility maximization problem, the intermediary maximizes profits, the government budget constraint holds, and the resource constraint and the money market clearing conditions are satisfied.

\section{Characterizing Equilibrium}

Now we characterize equilibria in this economy in which agents never hold over cash in either the goods market or the asset market, so that $a$ and $N$ are always zero. We do this in several steps. We first characterize the optimal choice of $c$ and $x$ given prices and arbitrary rules for $m, a$, and $z$, and we summarize these results in Proposition 1. We then characterize the trading rule $z$, given an arbitrary rule for $m$ and $a$ and the optimal rules for $c$ and $x$, and we summarize these results in Proposition 2. In Proposition 3, we solve for equilibrium $c, x, z$, and money holdings $m$ under the assumption that both $a$ and $N$ are always zero. In Proposition 4, we characterize the equilibrium bond holdings. In Proposition 5, we provide sufficient conditions on the money growth process and the endowments process to ensure that $a$ and $N$ are always zero. 
It simplifies our analysis to use the sequence of budget constraints (6) to substitute out for agents' bond holdings and replace these constraints with a single period 0 constraint on agents' transfers of cash between the asset market and the goods market. To that end, define period 0 prices $Q\left(\mu^{t}\right)$ for a unit of cash delivered in the asset market in period $t$ in state $\mu^{t}$ as follows. Let $Q\left(\mu_{1}\right)=q\left(\mu_{1}\right)$ and $Q\left(\mu^{t}\right)=q\left(\mu^{t-1}, \mu_{t}\right) Q\left(\mu^{t-1}\right)$. Accordingly, any bounded allocation and bond holdings that satisfy (6) also satisfy a period 0 budget constraint:

$$
\begin{gathered}
\bar{B} \geq \sum_{t=1}^{\infty} \int Q\left(\mu^{t}\right) \int_{y^{t-1}}\left\{P\left(\mu^{t}\right)\left[x\left(\mu^{t}, y^{t-1}\right)+\gamma\right] z\left(\mu^{t}, y^{t-1}\right)+\right. \\
\left.N\left(\mu^{t}, y^{t-1}\right)-N\left(\mu^{t-1}, y^{t-2}\right)\right\} f\left(y^{t-1}\right) d y^{t-1} d \mu^{t} .
\end{gathered}
$$

Thus, the consumer's problem can be restated as follows: choose real money holdings $m$ and $a$, trading rule $z$, consumption and transfers $c$ and $x$, and cash in the asset market $N$ subject to constraints (3)-(5) and (10).

Consider first an agent's optimal choice of consumption $c\left(\mu^{t}, y^{t-1}\right)$ and transfers of real balances $x\left(\mu^{t}, y^{t-1}\right)$ given prices $Q\left(\mu^{t}\right), P\left(\mu^{t}\right)$, arbitrary feasible choices of real money holdings $m\left(\mu^{t}, y^{t-1}\right)$ and $a\left(\mu^{t}, y^{t-1}\right)$, and a trading rule $z\left(\mu^{t}, y^{t-1}\right)$. These choices maximize the Lagrangian corresponding to the consumer's problem. Let $\nu\left(\mu^{t}, y^{t-1}\right)$ be the multiplier on (3) and $\lambda$ be the multiplier on (10). The first-order condition corresponding to $c$ is, then,

$$
\beta^{t} U^{\prime}\left(c\left(\mu^{t}, y^{t-1}\right)\right) g\left(\mu^{t}\right) f\left(y^{t-1}\right)=\nu\left(\mu^{t}, y^{t-1}\right) .
$$

The first-order condition corresponding to $x$ is

$$
\lambda Q\left(\mu^{t}\right) P\left(\mu^{t}\right) z\left(\mu^{t}, y^{t-1}\right) f\left(y^{t-1}\right)=\nu\left(\mu^{t}, y^{t-1}\right) z\left(\mu^{t}, y^{t-1}\right) .
$$

For those states such that $z\left(\mu^{t}, y^{t-1}\right)=1$, these two first-order conditions imply that

$$
\beta^{t} U^{\prime}\left(c\left(\mu^{t}, y^{t-1}\right)\right) g\left(\mu^{t}\right)=\lambda Q\left(\mu^{t}\right) P\left(\mu^{t}\right) .
$$


Since all agents are identical in period 0, the multipliers in the Lagrangian are the same for all agents. In summary:

Proposition 1. All agents who choose to pay the fixed cost for a given aggregate state $\mu^{t}$ have identical consumption $c\left(\mu^{t}, y^{t-1}\right)=c_{T}\left(\mu^{t}\right)$, for some function $c_{T}$. Agents who choose not to pay the fixed cost have zero transfers and consumption given by

$$
c\left(\mu^{t}, y^{t-1}\right)=m\left(\mu^{t}, y^{t-1}\right)-a\left(\mu^{t}, y^{t-1}\right)
$$

Next consider an agent's optimal choice of whether to pay the fixed cost to trade given prices $Q\left(\mu^{t}\right), P\left(\mu^{t}\right)$ and arbitrary feasible choices of real money holdings in the goods market $m\left(\mu^{t}, y^{t-1}\right), a\left(\mu^{t}, y^{t-1}\right)$. From Proposition 1, we have the form of the optimal consumption and transfer rules corresponding to the choices of $z=1$ and $z=0$. Substituting these rules into (7) and (10) gives the problem of choosing $c_{T}\left(\mu^{t}\right)$ and $z\left(\mu^{t}, y^{t-1}\right)$ to maximize

$$
\begin{aligned}
& \sum_{t=0}^{\infty} \beta^{t} \iint U\left(c_{T}\left(\mu^{t}\right)\right) z\left(\mu^{t}, y^{t-1}\right) g\left(\mu^{t}\right) f\left(y^{t-1}\right) d \mu^{t} d y^{t-1}+ \\
& \sum_{t=0}^{\infty} \beta^{t} \iint U\left(m\left(\mu^{t}, y^{t-1}\right)-a\left(\mu^{t}, y^{t-1}\right)\right)\left[1-z\left(\mu^{t}, y^{t-1}\right)\right] g\left(\mu^{t}\right) f\left(y^{t-1}\right) d \mu^{t} d y^{t-1}
\end{aligned}
$$

subject to the constraint

$$
\begin{aligned}
& \bar{B} \geq \sum_{t=0}^{\infty} \iint Q\left(\mu^{t}\right)\left[N\left(\mu^{t}, y^{t-1}\right)-N\left(\mu^{t-1}, y^{t-2}\right)\right] f\left(y^{t-1}\right) d \mu^{t} d y^{t-1}+ \\
& \sum_{t=0}^{\infty} \iint Q\left(\mu^{t}\right) P\left(\mu^{t}\right)\left\{c_{T}\left(\mu^{t}\right)+\gamma-\left[m\left(\mu^{t}, y^{t-1}\right)-a\left(\mu^{t}, y^{t-1}\right)\right] z\left(\mu^{t}, y^{t-1}\right)\right\} \\
& \quad \times f\left(y^{t-1}\right) d \mu^{t} d y^{t-1} .
\end{aligned}
$$

Let $\eta$ denote the Lagrange multiplier on (14), and consider the following variational argument. 
Given a state $\left(\mu^{t}, y^{t-1}\right)$, the increment to the Lagrangian of setting $z\left(\mu^{t}, y^{t-1}\right)=1$ in this

$$
\begin{aligned}
& \beta^{t} U\left(c_{T}\left(\mu^{t}\right)\right) g\left(\mu^{t}\right) f\left(y^{t-1}\right)- \\
& \eta Q\left(\mu^{t}\right) P\left(\mu^{t}\right)\left\{c_{T}\left(\mu^{t}\right)+\gamma-\left[m\left(\mu^{t}, y^{t-1}\right)-a\left(\mu^{t}, y^{t-1}\right)\right]\right\} f\left(y^{t-1}\right),
\end{aligned}
$$

which is simply the direct utility gain $U\left(c_{T}\left(\mu^{t}\right)\right)$ minus the cost of the required transfers. The increment to the Lagrangian of setting $z\left(\mu^{t}, y^{t-1}\right)=0$ in this state is

$$
\beta^{t} U\left(m\left(\mu^{t}, y^{t-1}\right)-a\left(\mu^{t}, y^{t-1}\right)\right) g\left(\mu^{t}\right) f\left(y^{t-1}\right)
$$

which is simply the direct utility gain since there are no transfers. The first-order condition with respect to $c_{T}$ is

$$
\beta^{t} U^{\prime}\left(c_{T}\left(\mu^{t}\right)\right) g\left(\mu^{t}\right)=\eta Q\left(\mu^{t}\right) P\left(\mu^{t}\right)
$$

Subtracting (16) from (15) and using (17), we see that it is optimal to set $z\left(\mu^{t}, y^{t-1}\right)=1$ if $h\left(m\left(\mu^{t}, y^{t-1}\right)-a\left(\mu^{t}, y^{t-1}\right) ; c_{T}\left(\mu^{t}\right)\right)>0$, where

$$
h\left(m-a ; c_{T}\right)=U\left(c_{T}\right)-U^{\prime}\left(c_{T}\right)\left[\left(c_{T}+\gamma\right)-(m-a)\right]-U(m-a) .
$$

Note that $h$ is strictly convex in the argument $m-a$, it attains its minimum at $m-a=c_{T}$, and it is negative at this minimum if $\gamma>0$. Define the cutoffs $y_{L}\left(c_{T}, \mu\right), y_{H}\left(c_{T}, \mu\right)$ as the solutions to

$$
h\left(\frac{y}{\mu}, c_{T}\right)=0
$$

when both of these solutions exist. If (19) is negative for all $y / \mu<c_{T}$, then set $y_{L}\left(c_{T}, \mu\right)=0$; if it is negative for all $y / \mu>c_{T}$, then set $y_{H}\left(c_{T}, \mu\right)=\infty$. Thus, an agent's decision to trade follows a cutoff rule as illustrated in Figure 1. In summary: 
Proposition 2. Given traders' consumption $c_{T}\left(\mu^{t}\right)$, agents choose $z\left(\mu^{t}, y^{t-1}\right)=0$ if $m\left(\mu^{t}, y^{t-1}\right)-a\left(\mu^{t}, y^{t-1}\right) \in\left(\frac{y_{L}\left(c_{T}\left(\mu^{t}\right), \mu_{t}\right)}{\mu_{t}}, \frac{y_{H}\left(c_{T}\left(\mu^{t}\right), \mu_{t}\right)}{\mu_{t}}\right)$, and they choose $z\left(\mu^{t}, y^{t-1}\right)=1$ otherwise.

Next, we suppose that agents do not carry over cash either in the asset market or in the goods market, so that $N$ and $a$ are always zero. We first characterize the rest of the equilibrium given these suppositions and then provide sufficient conditions for these suppositions to hold.

If agents never carry over cash in either the asset market or the goods market, then (4), (8), and (9) imply that $P\left(\mu^{t}\right)=M\left(\mu^{t}\right) / Y$, money holdings are given by $m\left(\mu^{t}, y^{t-1}\right)=$ $y_{t-1} / \mu_{t}$, and consumption of nontraders is $c\left(\mu^{t}, y^{t-1}\right)=y_{t-1} / \mu_{t}$. Substituting the nontraders' consumption into the resource constraint (8) and using the cutoff rules defined in (19) gives

$$
\left(c_{T}+\gamma\right)\left[F\left(y_{L}\right)+1-F\left(y_{H}\right)\right]+\frac{1}{\mu_{t}} \int_{y_{L}}^{y_{H}} y f(y) d y=Y,
$$

where we have suppressed explicit dependence of $c_{T}, y_{H}$, and $y_{L}$ on $\mu^{t}$. Clearly, these cutoff points and the consumption levels of traders depend only on $\mu_{t}$, while the consumption level of nontraders depends only on $\left(\mu_{t}, y_{t-1}\right)$. The equilibrium values of the cutoff points and the consumption of traders solve equations (19) and (20). Fix $\mu_{t}$ and use (19) to solve for $y_{L}$ and $y_{H}$ as functions of $c_{T}$; then note that the left side of (20) is continuous and strictly monotonic in $c_{T}$ and is less than $Y$ for $c_{T}=0$ and greater than $Y$ as $c_{T}$ becomes large. Thus, these equations have a unique solution for the equilibrium values of traders' consumption and cutoffs for any money growth rate $\mu$.

Note that if the fixed cost $\gamma$ is zero, then from (19), $y_{H}=y_{L}$, all consumers are traders, and their consumption $c=Y$ is independent of the money injection. In contrast, if the fixed 
cost is positive, then some consumers are nontraders and money injections have distributional effects. In summary:

Proposition 3. Under the suppositions that $a$ and $N$ are always zero, the equilibrium allocations satisfy

$$
c\left(y_{t-1}, \mu_{t}\right)= \begin{cases}y_{t-1} / \mu_{t} & \text { if } y_{t-1} \in\left(y_{L}\left(\mu_{t}\right), y_{H}\left(\mu_{t}\right)\right) \\ c_{T}\left(\mu_{t}\right) & \text { otherwise }\end{cases}
$$

where the functions $y_{L}(\mu), y_{H}(\mu), c_{T}(\mu)$ are the solutions to (19) and (20).

The bond holdings in this equilibrium have a simple form. For each aggregate state $\mu^{t}$, all agents purchase an identical portfolio of bonds. That is, $B\left(\mu^{t}, \mu_{t+1}, y^{t-1}, y_{t}\right)$ does not depend on individual histories $y^{t-1}$. To see this, note that we can iterate on the sequence of budget constraints (6) to get

$$
\begin{aligned}
& B\left(\mu^{t}, \mu_{t+1}, y^{t-1}, y_{t}\right)=P\left(\mu^{t+1}\right)\left[x\left(\mu^{t+1}, y_{t}\right)+\gamma\right] z\left(\mu^{t+1}, y_{t}\right)+ \\
& \quad \sum_{s=t+2}^{\infty} \int_{\mu^{s} \mid \mu^{t+1}} \frac{Q\left(\mu^{s}\right)}{Q\left(\mu^{t+1}\right)} \int_{y_{s-1}} P\left(\mu^{s}\right)\left[x\left(\mu^{s}, y_{s-1}\right)+\gamma\right] z\left(\mu^{s}, y_{s-1}\right) f\left(y_{s-1}\right) d y_{s-1} d \mu^{s} .
\end{aligned}
$$

Since the right side of $(21)$ does not depend on $y^{t-1}$, neither does the left side. We know, then, from (2) that each agent, regardless of individual history, buys an equal share of the new government debt issued. Then, using (6) and (1), we have that in period $t-1$ in state $\mu^{t-1}$, agents buy the following bonds to pay off in $t$ in state $\mu^{t}$ :

Proposition 4. For all realizations of $\mu_{t}$ and $y_{t-1}$ such that the agent would be a nontrader in period $t$ - namely, those that satisfy $y_{t-1} \in\left(y_{L}\left(\mu_{t}\right), y_{H}\left(\mu_{t}\right)\right)$-the agent buys bonds providing for a payoff that does not depend on the endowment shock:

$$
B\left(\mu^{t}, y^{t-1}\right)=\int_{\mu_{t+1}} q\left(\mu^{t+1}\right) B\left(\mu^{t+1}\right) d \mu_{t+1}
$$


For all realizations of $y_{t-1}$ such that the agent would be a trader, the agent buys bonds providing for the same constant payoff as a nontrader plus the contingent payoff required to pay for the appropriate transfer in period t, that is,

$$
B\left(\mu^{t}, y_{t-1}\right)=P\left(\mu^{t}\right)\left[x\left(\mu_{t}, y_{t-1}\right)+\gamma\right]+\int_{\mu_{t+1}} q\left(\mu^{t+1}\right) B\left(\mu^{t+1}\right) d \mu_{t+1}
$$

In period $t$ the government will be issuing new money $M\left(\mu^{t}\right)-M\left(\mu^{t-1}\right)$ to purchase some of the outstanding government bonds $B\left(\mu^{t}\right)$. In period $t-1$, agents plan so that if they are traders in $t$, they will have enough extra bonds to purchase both the amount of money injection they need to carry out their desired transfer and the amount of the new government debt issued. In the aggregate, these traders purchase the entire money injection as well as the new government debt. In period $t-1$, agents plan so that if they are nontraders in $t$, they will only have enough bonds to purchase the new government debt issued. Thus, agents plan their portfolios so that their endowment shocks do not affect their overall wealth positions. They use bonds to provide insurance against next period's endowment shock.

We now develop conditions sufficient to guarantee that our suppositions hold. The condition for $N$ to be zero, so that agents in the asset market prefer to save using nominal bonds rather than money, is $\int q\left(\mu^{t}, \mu_{t+1}\right) d \mu_{t+1}<1$, which simply ensures that nominal interest rates are positive for all periods $t$ and states $\mu^{t}$. In terms of marginal utilities, this condition can be written as

$$
U^{\prime}\left(c_{T}\left(\mu_{t}\right)\right)>\beta \int_{\mu_{t+1}} \frac{U^{\prime}\left(c_{T}\left(\mu_{t+1}\right)\right)}{\mu_{t+1}} g\left(\mu_{t+1} \mid \mu^{t}\right) d \mu_{t+1} .
$$

To develop the condition for $a$ to be zero, we proceed as follows. Let $Q\left(\mu^{t}\right)$ and $P\left(\mu^{t}\right)$ be the prices constructed above when $a$ and $N$ are always zero. Consider a class of 
potential deviations by a single agent when faced with these prices. In particular, consider the problem of an agent from period $t$ on, starting in state $\left(\mu^{t}, y^{t-1}\right)$ with arbitrary bond holdings $\bar{B}\left(\mu^{t}, y^{t-1}\right)$ and money holdings $\bar{m}\left(\mu^{t}, y^{t-1}\right)$, with budget constraints of the form given in (6), taking these prices $Q\left(\mu^{t}\right)$ and $P\left(\mu^{t}\right)$ as given. Here, as before, we can turn the sequence of budget constraints into a single budget constraint, except that now it starts in period $t$ instead of period 0 .

The first-order conditions for the period $t$ problem will be identical to those of the period 0 problem, except for the multiplier on the single budget constraint; that will differ because $\bar{B}\left(\mu^{t}, y^{t-1}\right)$ and $\bar{m}\left(\mu^{t}, y^{t-1}\right)$ are arbitrarily chosen and are not the equilibrium bond and money holdings. The first-order conditions for the consumption of traders from the period 0 problem are given in (17), while the first-order conditions for $c_{T}$ in periods $s \geq t$ from the period $t$ problem with arbitrary asset holdings are of the same form with some new multiplier which depends on $\bar{B}\left(\mu^{t}, y^{t-1}\right)$ and $\bar{m}\left(\mu^{t}, y^{t-1}\right)$. Hence, the consumption of this agent when the agent trades is given by a function $c_{T}\left(\mu_{s} ; \tilde{\eta}\right)$ that solves $U^{\prime}\left(c_{T}\left(\mu_{s} ; \tilde{\eta}\right)\right)=\tilde{\eta} U^{\prime}\left(c_{T}\left(\mu_{s}\right)\right)$ for some $\tilde{\eta} \geq 0$, which should be thought of as the ratio of the original to the new multiplier. Given $c_{T}\left(\mu_{s} ; \tilde{\eta}\right)$, let $y_{L}(\mu ; \tilde{\eta})$ and $y_{H}(\mu ; \tilde{\eta})$ be the associated solutions to $(19)$.

For this agent to choose $a\left(\mu^{t}, y^{t-1}\right)=0$, when $a$ is constrained to be zero in all future periods, it is sufficient that, for all $\mu^{t}, \tilde{\eta}$, and $a$,

$$
\begin{aligned}
& U^{\prime}\left(y_{H}\left(\mu_{t} ; \tilde{\eta}\right)\right)>\beta \int_{\mu_{t+1}} \int_{y_{L}\left(\mu_{t+1} ; \tilde{\eta}\right)-a}^{y_{H}\left(\mu_{t+1} ; \tilde{\eta}\right)-a} U^{\prime}\left(\frac{a+y_{t}}{\mu_{t+1}}\right) \frac{f\left(y_{t}\right)}{\mu_{t+1}} g\left(\mu_{t+1} \mid \mu^{t}\right) d y_{t} d \mu_{t+1}+ \\
& \beta \int_{\mu_{t+1}} \frac{U^{\prime}\left(c_{T}\left(\mu_{t+1} ; \tilde{\eta}\right)\right)}{\mu_{t+1}}\left[F\left(y_{L}\left(\mu_{t+1} ; \tilde{\eta}\right)-a\right)+1-F\left(y_{H}\left(\mu_{t+1} ; \tilde{\eta}\right)-a\right)\right] g\left(\mu_{t+1} \mid \mu^{t}\right) d \mu_{t+1} .
\end{aligned}
$$

Notice that (25) simply requires that the shadow nominal interest rate for each individual be positive, regardless of the shock $\mu$, the individual's wealth as reflected in $\tilde{\eta}$, or the individual's 
choice of $a$ in the current period. Finally, we get

Proposition 5. It is optimal for an agent never to hold over cash in the asset market if (24) holds for all values of $\mu^{t}$. It is optimal for an agent never to hold over cash in the goods market if (25) holds.

Proof. When (24) holds, nominal interest rates in the asset market are positive, so agents hold over no cash in the asset market. To see that $a$ is identically equal to zero, suppose to the contrary that there is a plan with $a>0$ for at least one state that gives higher utility. Consider, first, a plan in which $a>0$ in at most a finite set of periods. Let $t$ be the last such period, and suppose that $a\left(\mu^{t}, y^{t-1}\right)>0$. In that period, the highest consumption that an agent with wealth level indexed by $\tilde{\eta}$ would choose is $y_{H}\left(\mu_{t} ; \tilde{\eta}\right)\left[\right.$ since $y_{H}\left(\mu_{t} ; \tilde{\eta}\right)>c_{T}\left(\mu_{t} ; \tilde{\eta}\right)$. Hence, the lowest an agent's shadow nominal interest rate could be is the level at which current consumption is $y_{H}\left(\mu_{t} ; \tilde{\eta}\right)$. Since $t$ is the last period in which $a$ is positive, (25) implies that lowering $a$ to zero is optimal. Hence, we have a contradiction. If no finite deviations raise utility - since consumption is bounded and $\beta<1$-no plan in which $a>0$ for an infinite set of periods gives higher utility than the one with $a$ identically equal to zero.

The following is a simpler condition sufficient to ensure that (25) holds. Let

$$
U^{\prime}\left(y_{H}\left(\mu_{t} ; \tilde{\eta}\right)\right)>\beta \int_{\mu_{t+1}} U^{\prime}\left(y_{L}\left(\mu_{t+1} ; \tilde{\eta}\right)\right) \frac{1}{\mu_{t+1}} g\left(s_{t+1} \mid s^{t}\right) d s_{t+1}
$$

for all $s^{t}$ and $\tilde{\eta}$. This condition clearly holds for small $\gamma$ and $\beta E_{t} 1 / \mu_{t+1}$ small.

\section{Asset Prices}

Now we develop the links between money injections and asset prices. The link that is introduced with market segmentation is how a trader's consumption responds to a money 
injection. We start with this link and then develop formulas for asset prices.

Recall from (17) that period 0 nominal asset prices are given by the traders' marginal utility of a dollar. Since $P\left(\mu^{t}\right)=M\left(\mu^{t}\right) / Y$, in order to characterize the response of asset prices to money injections, we need to determine how a trader's consumption responds to a money injection, namely, how $c_{T}\left(\mu_{t}\right)$ varies with $\mu_{t}$.

Consider a simple example in which $y$ takes on three values, $y_{0}<y_{1}<y_{2}$, with probabilities $f_{0}, f_{1}, f_{2}$, respectively. We conjecture an equilibrium in which, when money growth is $\bar{\mu}$, agents with the central value of the endowment $y_{1}$ choose not to trade and those with low and high endowments $y_{0}$ and $y_{2}$ choose to trade. Under this conjecture, for money growth shocks $\mu$ close to $\bar{\mu}$, from the resource constraint, traders each consume an equal share of traders' aggregate endowment plus the inflation tax levied on nontraders minus the fixed cost, or

$$
c_{T}(\mu)=\frac{y_{0} f_{0}+y_{2} f_{2}}{f_{0}+f_{2}}+\left(1-\frac{1}{\mu}\right) \frac{y_{1} f_{1}}{f_{0}+f_{2}}-\gamma .
$$

The corresponding cutoffs $y_{L}\left(c_{T}(\mu), \mu\right), y_{H}\left(c_{T}(\mu), \mu\right)$ are found from (19). This conjecture is valid as long as $y_{0}<y_{L}\left(c_{T}(\bar{\mu}), \bar{\mu}\right)<y_{1}<y_{H}\left(c_{T}(\bar{\mu}), \bar{\mu}\right)<y_{2}$. Sufficient conditions for this conjecture to hold are that traders' consumption as defined in (26) satisfies $c_{T}(\bar{\mu})=y_{1} / \bar{\mu}$ and $\gamma$ is sufficiently small. Under these conditions, the consumption of traders and nontraders when $\mu=\bar{\mu}$ is $y_{1} / \bar{\mu}$. As $\gamma$ gets small, the cutoffs $y_{L}\left(c_{T}(\bar{\mu}), \bar{\mu}\right) / \bar{\mu}$ and $y_{H}\left(c_{T}(\bar{\mu}), \bar{\mu}\right) / \bar{\mu}$ approach $c_{T}$, so that the above inequalities hold.

Clearly, an increase in the money growth rate $\mu$ raises the inflation tax levied on nontraders' real balances. In equilibrium, asset prices adjust to redistribute these inflation tax revenues to traders. In this example, the number of traders does not vary with the money 
injection, so the consumption of each trader increases. Specifically,

$$
\frac{d \log c_{T}}{d \log \mu}=\frac{\left(y_{1} f_{1}\right) / \mu}{c_{T}\left(f_{0}+f_{2}\right)},
$$

which is the ratio of the total consumption of nontraders to that of traders.

In general, a money injection increases the total amount consumed by traders and changes the number of agents who choose to become traders. If that number of agents does not increase much, the consumption of each trader increases. Of course, if the number increases enough, then the consumption of each trader can actually fall. In Appendix A we elaborate on this point.

Next we develop formulas for equilibrium asset prices. To get analytical results, we make the following assumptions. Let the $\log$ of money growth in period $t, \log \mu_{t}$, be normally distributed and have constant conditional variance over time. Let $\bar{\mu}$ be defined by $\log \bar{\mu}=$ $E \log \mu_{t}$, where $E$ is the unconditional expectation. Let $U(c)=c^{1-\sigma} /(1-\sigma)$, where $\sigma>0$. Let $\bar{c}_{T}$ denote the consumption of traders when money growth is equal to $\bar{\mu}$. To a first-order approximation, the log of a trader's marginal utility is given by

$$
\log U^{\prime}\left(c_{T t}\right)=\log U^{\prime}\left(\bar{c}_{T}\right)-\phi\left(\log \mu_{t}-\log \bar{\mu}\right),
$$

where

$$
\phi=\sigma \frac{d \log c_{T}}{d \log \mu},
$$

evaluated at $\mu=\bar{\mu}$. The parameter $\phi$ is the elasticity of a trader's marginal utility with respect to a money injection.

With these assumptions, we will analyze the relation between money and interest rates. These interest rates are calculated from nominal and real bond prices. In what follows, 
we suppress reference to the state $\mu^{t}$ and write the price of an $n$-period bond that $\operatorname{costs} q_{t}^{n}$ dollars at $t$ and pays one dollar in all states at $t+n$ as

$$
q_{t}^{n}=\int \frac{Q\left(\mu^{t}, \mu^{n}\right)}{Q\left(\mu^{t}\right)} d \mu_{n}=\beta^{n} E_{t} \frac{U^{\prime}\left(c_{T t+n}\right)}{U^{\prime}\left(c_{T t}\right)} \frac{P_{t}}{P_{t+n}} .
$$

Taking logs of (30) and using the result that for any log-normal variable $x, \log E x=E \log x+$ $\operatorname{var} \log x / 2$, we write the $\log$ of bond prices as

(31) $\log q_{t}^{n}=n \log \beta+E_{t} \log \frac{U^{\prime}\left(c_{T t+n}\right)}{P_{t+n}}-\log \frac{U^{\prime}\left(c_{T t}\right)}{P_{t}}+\frac{1}{2} \operatorname{var}_{t}\left(\log \frac{U^{\prime}\left(c_{T t+n}\right)}{P_{t+n}}-\log \frac{U^{\prime}\left(c_{T t}\right)}{P_{t}}\right)$.

Since output is constant, inflation is given by $\log P_{t+n}=\log P_{t}+\sum_{j=1}^{n} \mu_{t+j}$, and using the approximation (28), we write the log of bond prices as

$$
\log q_{t}^{n}-\log \bar{q}^{n}=-\phi E_{t}\left(\log \mu_{t+n}-\log \mu_{t}\right)-E_{t} \sum_{j=1}^{n}\left(\log \mu_{t+j}-\log \bar{\mu}\right)
$$

where $\log \bar{q}^{n}=n(\log \beta-\log \bar{\mu})+E \frac{1}{2} \operatorname{var}_{t}\left(\phi \log \mu_{t+n}+\sum_{j=1}^{n} \log \mu_{t+j}\right)$.

We use these bond prices to define yields and forward rates. The yield on an $n$-period nominal bond is $r_{t}^{n}=-\frac{1}{n} \log q_{t}^{n}$. The forward interest rate between periods $t+n$ and $t+n+1$ in period $t$ is $f_{t}^{n}=\log \left(q_{t}^{n} / q_{t}^{n+1}\right)$. Thus, the forward rate is the rate of return between periods $t+n$ and $t+n+1$ that can be guaranteed in period $t$. Clearly, then, the yield is the average of the forward rates: $r_{t}^{n}=\frac{1}{n} \sum_{j=1}^{n} f_{t}^{j-1}$.

\section{Liquidity Effects}

Now we present examples to illustrate the impact of money injections on interest rates under alternative assumptions about the stochastic process for money growth and the degree of market segmentation. 
In the standard model, $\gamma=0$, so $\phi=0$ and real interest rates are constant. From (32), we know that nominal bond prices are given by

$$
\log q_{t}^{n}-\log \bar{q}^{n}=-E_{t}\left(\sum_{j=1}^{n} \log \mu_{t+j}-\log \bar{\mu}\right)=E_{t} \log \frac{P_{t}}{P_{t+n}}-n \log \frac{1}{\bar{\mu}}
$$

which is the deviation of cumulative expected inflation between period $t$ and $t+n$ from its unconditional mean. We call this term the expected inflation effect.

In our model with $\gamma>0$, there is also a segmentation effect. This effect is the impact of money injections on the real interest rate and is captured by the term $-\phi E_{t}\left(\log \mu_{t+n}-\log \mu_{t}\right)$ in (32). A money growth shock that increases $\mu_{t}$ also increases the consumption of traders at $t$ and drives down their marginal utility at $t$; this part of the effect, by itself, raises all bond prices by $\phi\left(\log \mu_{t}-\log \bar{\mu}\right)$. If the money growth shock raises expected money growth at $t+n$ as well, then it raises future consumption and lowers future marginal utility for traders; this part of the effect, by itself, lowers all bond prices by $\phi E_{t}\left(\log \mu_{t+n}-\log \bar{\mu}\right)$.

The overall magnitude of the segmentation effect depends on two parameters: the elasticity of the marginal utility of traders with respect to money growth $\phi$ and the persistence of a money growth shock on expected future money growth $E_{t}\left(\log \mu_{t+n}-\log \mu_{t}\right)$. The segmentation effect increases the higher is $\phi$, that is, the more responsive is a trader's marginal utility to a money injection. This effect is smaller the greater is the persistence of money growth. If money growth is temporary, then a given money injection will lead to a temporary increase in traders' consumption and, hence, a relatively large drop in the real interest rate, driving down the nominal interest rate. As the shock to money growth becomes more persistent, a given money injection leads to a more permanent increase in traders' consumption and, hence, to a smaller drop in the real interest rate. 
Example 1 (Autoregressive money growth). Assume that money injections satisfy

$$
\log \mu_{t+1}=(1-\rho) \log \bar{\mu}+\rho \log \mu_{t}+\varepsilon_{t+1},
$$

where $\varepsilon_{t+1}$ is a normal, i.i.d. innovation with mean zero and variance $\sigma_{\varepsilon}^{2}$. The nominal bond price in (32) then becomes

$$
\log q_{t}^{n}-\log \bar{q}^{n}=\frac{1-\rho^{n}}{1-\rho}[(1-\rho) \phi-\rho]\left(\log \mu_{t}-\log \bar{\mu}\right)
$$

Here the segmentation effect is captured by the term $\left(1-\rho^{n}\right) \phi\left(\log \mu_{t}-\log \bar{\mu}\right)$. The sign of the segmentation effect is positive, so with segmented markets, higher money growth leads to higher real bond prices and, hence, lower real interest rates. Notice that if

$$
\phi>\frac{\rho}{1-\rho},
$$

then the segmentation effect dominates the expected inflation effect, and a money injection leads to a fall in nominal interest rates.

Consider now the impact of the money shock on the forward rate curve and the yield curve. From $(33), f_{t}^{n}-\bar{f}^{n}=\rho^{n}[(\rho-1) \phi+\rho]\left(\log \mu_{t}-\log \bar{\mu}\right)$ and

$$
r_{t}^{n}-\bar{r}^{n}=\frac{1}{n} \frac{\left(1-\rho^{n}\right)}{(1-\rho)}[(\rho-1) \phi+\rho]\left(\log \mu_{t}-\log \bar{\mu}\right)
$$

When (34) holds, so that the segmentation effect dominates the expected inflation effect, a money injection lowers the shorter forward rates and yields by more than the longer forward rates and yields and thus steepens both the forward rate curve and the yield curve.

Now consider the dynamics of interest rates of different maturities. The $n$-period yields expected in period $t+k$ following a money injection in $t$ are given by

$$
E_{t} r_{t+k}^{n}-\bar{r}^{n}=\rho^{k}\left(r_{t}^{n}-\bar{r}^{n}\right)
$$


Thus, each yield returns to its mean value at rate $\rho$. As long as the segmentation effect dominates the expected inflation effect, we have the following: transient money growth shocks cause sharp but temporary declines in nominal rates while persistent money growth shocks cause smaller but more persistent declines in nominal rates. Note that if the segmentation effect dominates the expected inflation effect in (35) and (36), then a money injection lowers interest rates of all maturities $n$ at all horizons $t+k$. In the standard model, the expected inflation effect dominates, and a money injection raises nominal rates of all maturities at all horizons.

So far, we have worked out relations between money injections and interest rates for a simple money growth process. Now we develop these relations when money growth has a general moving-average representation:

$$
\log \mu_{t}-\log \bar{\mu}=\sum_{j=0}^{\infty} \theta_{j} \varepsilon_{t-j}
$$

where $\varepsilon_{t-j}$ are independent and $N\left(0, \sigma_{\varepsilon}^{2}\right)$. The basic building block for pricing nominal assets is the pricing kernel, namely, the state-contingent marginal rate of substitution between a dollar in period $t$ and a dollar in period $t+1$. This pricing kernel is

$$
m_{t+1}=\beta \frac{U^{\prime}\left(c_{T t+1}\right)}{U^{\prime}\left(c_{T t}\right)} \frac{P_{t}}{P_{t+1}}
$$

and can be used to price any nominal asset. The price of a one-period nominal bond is given by $q_{t}^{1}=E_{t} m_{t+1}$ and that of an $n$-period nominal bond by $q_{t}^{n}=E_{t} m_{t+1} m_{t+2} \ldots m_{t+n}$. Given our approximation to the log of a trader's marginal utility (28), we obtain

$$
-\log m_{t+1}=\delta+(\phi+1)\left(\log \mu_{t+1}-\log \bar{\mu}\right)-\phi\left(\log \mu_{t}-\log \bar{\mu}\right)
$$


where $\delta=-\log \beta+\log \bar{\mu}$ and $\phi$ is given in (29). Equations (37) and (39) then imply that the pricing kernel is log-normal with an infinite moving-average representation

$$
-\log m_{t+1}=\delta+\sum_{j=0}^{\infty} \alpha_{j} \varepsilon_{t+1-j}
$$

with

$$
\alpha_{0}=(\phi+1) \theta_{0}, \text { and for } j \geq 0, \alpha_{j+1}=\phi\left(\theta_{j+1}-\theta_{j}\right)+\theta_{j+1} \text {. }
$$

Notice that $\alpha_{0}=-\partial \log \left[U^{\prime}\left(c_{T t}\right) / P_{t}\right] / \partial \varepsilon_{t}$ is the impact of a money shock on the marginal utility of a dollar in period $t$ while $\alpha_{j+1}=-E_{t} \partial \log \left[U^{\prime}\left(c_{T t+j+1}\right) P_{t} / U^{\prime}\left(c_{T t+j}\right) P_{t+j+1}\right] /$ $\partial \varepsilon_{t}$ is the impact of a money shock on the expected nominal interest rate between periods $t+j$ and $t+j+1$. This effect can be decomposed into two pieces: $\theta_{j+1}=E_{t} \partial \log \mu_{t+j+1} / \partial \varepsilon_{t}$ is the effect of the shock on expected inflation from period $t+j$ to period $t+j+1$, while $\phi\left(\theta_{j+1}-\theta_{j}\right)=-E_{t} \partial \log \left[U^{\prime}\left(c_{T t+j+1}\right) / U^{\prime}\left(c_{T t+j}\right)\right] / \partial \varepsilon_{t}$ is the effect of the shock on the expected one-period real interest rate from period $t+j$ to period $t+j+1$. Clearly, $\phi\left(\theta_{j+1}-\theta_{j}\right)$ reflects the market segmentation effect on the one-period real interest rate.

With the assumed process for money growth (37), the bond price formulas (32) imply that

$$
\begin{aligned}
& f_{t}^{n}=\bar{f}^{n}+\sum_{j=1}^{\infty} \alpha_{j+n} \varepsilon_{t+1-j} \\
& r_{t}^{n}=\bar{r}^{n}+\frac{1}{n} \sum_{j=0}^{\infty}\left(A_{n+j}-A_{j}\right) \varepsilon_{t-j},
\end{aligned}
$$

where $A_{j}=\sum_{i=0}^{j} \alpha_{i}$ and $\bar{f}^{n}$ and $\bar{r}^{n}$ are mean rates that we discuss later. Notice that with $n=1,(43)$ reduces to $r_{t}^{1}=\bar{r}^{1}+\sum_{j=1}^{\infty} \alpha_{j} \varepsilon_{t+1-j}$.

Example 2 (Long-memory processes). Now consider a fractionally integrated process for money growth and inflation. We are motivated by the findings (surveyed in Baillie 1996) that 
a single-factor long-memory model can mimic the slow decay of the observed autocorrelations of inflation. With such a process, we find that a persistent increase in the money growth rate leads first to a decline in nominal interest rates and then eventually to an increase in these rates. As a result, this increase in the money growth rate twists the forward rate curve, lowering short-term forward rates and raising long-term ones. Again, at least since Friedman (1968), economists have argued that money injections have these effects on interest rates.

Let money growth and inflation follow a fractionally integrated process of the form $(1-L)^{d} \mu_{t}=\varepsilon_{t}$, where $-1 / 2<d<1 / 2$. The first-order autocorrelation of this process is $d /(1-d)$. The coefficients of the moving-average representation of the money growth and inflation process (37) satisfy the following recursion:

$$
\theta_{j}=\left(1-\frac{1-d}{j}\right) \theta_{j-1}
$$

for $j \geq 1$. The parameter $d$ controls the rate of decay of the moving-average coefficients. These coefficients decay at a rate $(1-d) / j<1$. For large $j$, this rate approaches 0 , which is the source of the long memory.

A long-memory shock to money growth leads initially to lower short-term nominal interest rates and then to higher ones, and it twists the forward rate curve as follows. From (43) and (42), we know that the impact of a money growth shock in $t$ on the expected oneperiod interest rate in period $t+j$ and on the forward rate of maturity $j$ in period $t$ is given by $\alpha_{j}$. Using (41) and (44), we obtain

$$
\alpha_{j}=-\phi \frac{(1-d)}{j} \theta_{j-1}+\left[1-\frac{(1-d)}{j}\right] \theta_{j-1},
$$

where the first term is the segmentation effect and the second is the expected inflation effect. Since the coefficients $\theta_{j}$ are all positive, for large enough $j$ the expected inflation effect must 
dominate the segmentation effect and $\alpha_{j}$ must be positive. If $\phi>d /(1-d)$, then for $j=1$, the segmentation effect outweighs the expected inflation effect, and so for small $j, \alpha_{j}$ is negative. If we ignore integers, we see that $\alpha_{j}$ goes from negative to positive at $j^{*}=(1+\phi)(1-d)$. Notice that the more segmented is the market, the longer is the period in which the segmentation effect outweighs the expected inflation effect.

\section{The Average Term Structure of Interest Rates}

Finally, we consider the implications of monetary policy for the average yields of bonds of different maturities in the segmented markets model. Two measures of the term structure of interest rates are the forward rate curve and the yield curve. In the data, both of these are upward-sloping, at least for maturities of up to seven years. (See for example, Campbell, Lo, and MacKinlay 1997.) In the standard model, persistent money growth shocks produce downward-sloping forward rate and yield curves on average. In our model, if markets are sufficiently segmented, then these shocks produce upward-sloping forward rate and yield curves on average.

From (31), we have that the average nominal bond price is

$$
\log \bar{q}^{n}=n(\log \beta-\log \bar{\mu})+E \frac{1}{2} \operatorname{var}_{t}\left(\log \frac{U^{\prime}\left(c_{T t+n}\right)}{P_{t+n}}-\log \frac{U^{\prime}\left(c_{T t}\right)}{P_{t}}\right)
$$

Thus, the average forward rate and yield curves are given, respectively, by

$$
\begin{aligned}
\bar{f}^{n}= & \log \bar{\mu}-\log \beta+ \\
& E \frac{1}{2} \operatorname{var}_{t}\left(\log \frac{U^{\prime}\left(c_{T t+n}\right)}{P_{t+n}}-\log \frac{U^{\prime}\left(c_{T t}\right)}{P_{t}}\right)-\operatorname{var}_{t}\left(\log \frac{U^{\prime}\left(c_{T t+n+1}\right)}{P_{t+n+1}}-\log \frac{U^{\prime}\left(c_{T t}\right)}{P_{t}}\right) \\
\bar{r}^{n}= & \log \bar{\mu}-\log \beta-E \frac{1}{2 n} \operatorname{var}_{t}\left(\log \frac{U^{\prime}\left(c_{T t+n}\right)}{P_{t+n}}-\log \frac{U^{\prime}\left(c_{T t}\right)}{P_{t}}\right) .
\end{aligned}
$$


In Appendix B, we show that these simplify to

$$
\begin{aligned}
\bar{f}^{n} & =\log \bar{\mu}-\log \beta-\frac{1}{2} A_{n}^{2} \sigma_{\varepsilon}^{2} \\
\bar{r}^{n} & =\log \bar{\mu}-\log \beta-\frac{1}{2 n} \sum_{j=0}^{n-1} A_{j}^{2} \sigma_{\varepsilon}^{2}
\end{aligned}
$$

where $A_{j}=\sum_{i=0}^{j} \alpha_{i}$ and the coefficients $\alpha_{i}$ are the moving-average coefficients of the pricing kernel (40).

The model we have considered has only one type of money shock. In such a one-factor model, liquidity effects and the average slope of the forward rate curve are closely connected, as the following propositions show.

Proposition 6. If money growth shocks are persistent, so that $\theta_{j} \geq 0$ for all $j=0, \ldots, J$, then the forward rate curve is upward-sloping up to maturity $J$ if and only if there are $J$-period liquidity effects in the sense that $\alpha_{j} \leq 0$ for $j=1, \ldots, J$.

Proof. Since $A_{j}=\sum_{i=0}^{j} \alpha_{i}$, from (40) we have that $A_{j}=\phi \theta_{j}+\sum_{i=0}^{j} \theta_{i}$. Thus, if $\theta_{j} \geq 0$ for $j=0, \ldots, J$, then $A_{j} \geq 0$ for $j=0, \ldots, J$. Clearly, if $\alpha_{j} \leq 0$ for $j=1, \ldots, J$, then $A_{j}$ is decreasing in $j$ for $j=0, \ldots, J$, so that $A_{0}^{2} \geq A_{1}^{2} \geq A_{2}^{2} \geq \ldots \geq A_{J}^{2}$, and, from (48), the forward rate curve is upward-sloping. Conversely, if the forward rate curve is upward-sloping for $j=1, \ldots, J$, then $A_{0}^{2} \geq A_{1}^{2} \geq A_{2}^{2} \geq \ldots \geq A_{J}^{2}$. Since $A_{j} \geq 0, \alpha_{j} \leq 0$ for $j=1, \ldots, J$.

Proposition 7. If money injections have J-period liquidity effects in the sense that $\alpha_{j} \leq 0$ for $j=0, \ldots, J$ and money growth shocks are persistent and decay monotonically in the sense that $\theta_{j} \geq 0$ and $\theta_{j} \leq \theta_{j-1}$ for $j=0, \ldots, J$, then the more segmented are markets, the steeper is the forward rate curve. 
Proof. The slope of the forward rate curve between maturities $j-1$ and $j$ is given by $\left(A_{j-1}^{2}-A_{j}^{2}\right) / 2$. Clearly, $\left(A_{j-1}^{2}-A_{j}^{2}\right)=\left(A_{j-1}-A_{j}\right)\left(A_{j-1}+A_{j}\right)$, which equals $-\left[\phi\left(\theta_{j}-\theta_{j-1}\right)+\theta_{j}\right]\left[\phi\left(\theta_{j}+\theta_{j-1}\right)+\theta_{j}+2 \sum_{i=0}^{j-1} \theta_{i}\right]$.

Given the conditions on $\theta_{j}$, this expression is increasing in the segmentation parameter $\phi$.

To get some intuition for these results, observe from (47) that the average yield curve is upward-sloping if, on average, the conditional variance of the log of the $n$-period pricing kernel, written as

$$
\operatorname{var}_{t}\left(\log \frac{U^{\prime}\left(c_{T t+n+1}\right)}{P_{t+n+1}}-\log \frac{U^{\prime}\left(c_{T t}\right)}{P_{t}}\right)
$$

grows more slowly than $n$. Clearly, (50) is the variance of the long difference of the marginal utility of a dollar. Notice that if the marginal utility of a dollar follows a random walk, then this variance grows linearly with $n$, and thus, the average yield curve is flat. If the marginal utility of a dollar has a large temporary component, then this variance grows more slowly than $n$, and the yield curve is upward-sloping. In our model, shocks to money growth have a permanent effect on the price level, but only a temporary effect on the consumption of traders. For the yield curve to be upward-sloping, the temporary effect, due to market segmentation, must be large. (See Campbell and Mankiw 1987 and Cochrane 1988 for some discussion of the statistical properties of long differences.)

Consider again our two examples.

Example 1 (Autoregressive money growth). With AR1 money growth rates, recall that $\theta_{j}=$ $\rho^{j} \theta_{0}$, so that all the coefficients $\theta_{j}$ are positive and declining for all $j$, and hence, the hypotheses of Propositions 6 and 7 are satisfied. In the standard model, all the coefficients $\alpha_{j}$ are positive, 
so that the forward rate and yield curves are downward-sloping. In the segmented markets model, however, if $\phi$ is large enough to satisfy (34), then the forward rate and yield curves are upward-sloping at all maturities.

Example 2 (Long-memory processes). The moving-average coefficients of the long-memory money growth process satisfy (44), so that $\theta_{j} \geq 0$ and $\theta_{j}<\theta_{j-1}$ for all $j$, and hence, Propositions 6 and 7 apply. Recall that $\alpha_{j} \leq 0$ for $j=1, \ldots, j^{*}$, where $j^{*}=(1+\phi)(1-d)$. Thus, the forward rate curve and the yield curve are upward-sloping for $j=1, \ldots, j^{*}$. Notice that the more segmented is the market, the longer are the maturities for which the forward rate and yield curves are upward-sloping.

Propositions 6 and 7 do not directly apply to a model in which there are several types of money shocks. Consider, for example, a process for money growth with two types of shocks. Obviously, Propositions 6 and 7 do not apply directly here. However, the slopes of the forward and yield curves for the two-factor model are the sum of the slopes of yield curves corresponding to the two factors separately. In this sense, the propositions apply to each factor separately. (See Zin 1998 for a discussion of two-factor models.)

\section{Conclusion}

We have developed a tractable model that captures the idea that when a government injects money through an open market operation, only a fraction of the agents in the economy are on the other side of the transaction. We show that in such a model, money shocks can generate both persistent liquidity effects and twists in the forward rate curve. The model can also produce an upward-sloping yield curve on average. 


\section{Appendix A}

Here we present two additional examples illustrating the effect of money growth shocks on a trader's consumption.

First, let all agents have identical constant endowment $y$. In equilibrium, a fraction $\alpha$ of agents are traders and purchase the money injection from the government, and $1-\alpha$ are nontraders. Since agents must be indifferent between trading and not trading, the following condition must hold:

$$
U\left(c_{T}\right)-U^{\prime}\left(c_{T}\right)\left(c_{T}+\gamma-y / \mu\right)=U(y / \mu) .
$$

This equation has two solutions for $c_{T}$ : one with $c_{T}+\gamma>y / \mu$ and one with $c_{T}+\gamma<$ $y / \mu$. When the money injection is positive, traders must purchase real balances from the government, so the equilibrium solution satisfies $c_{T}+\gamma>y / \mu$. The fraction $\alpha$ adjusts to satisfy the resource constraint. Differentiating (51) with respect to $\mu$ gives

$$
\frac{d c_{T}}{d \mu}=\frac{\left[U^{\prime}(y / \mu)-U^{\prime}\left(c_{T}\right)\right] y / \mu^{2}}{U^{\prime \prime}\left(c_{T}\right)\left[c_{T}+\gamma-(y / \mu)\right]}<0 .
$$

Again, an increase in the money growth rate $\mu$ redistributes inflation tax revenues from nontraders to traders. Here, however, the number of traders increases so much that the amount of consumption per trader actually falls.

Next, consider the case in which $y$ has a continuous density. Differentiating (19)-(20) gives

$$
\begin{aligned}
& \left\{\left[F\left(y_{L}\right)+1-F\left(y_{H}\right)\right]+\mu f\left(y_{L}\right)\left(c_{T}+\gamma-\frac{y_{L}}{\mu}\right) \eta_{L}-\mu f\left(y_{H}\right)\left(c_{T}+\gamma-\frac{y_{H}}{\mu}\right) \eta_{H}\right\} \frac{d c_{T}}{d \mu} \\
& =\left(\frac{y_{L}}{\mu}-c_{T}-\gamma\right) f\left(y_{L}\right) \frac{y_{L}}{\mu}+\left(c_{T}+\gamma-\frac{y_{H}}{\mu}\right) f\left(y_{H}\right) \frac{y_{H}}{\mu}+\frac{1}{\mu} \int_{y_{L}}^{y_{H}} \frac{y}{\mu} f(y) d y
\end{aligned}
$$


where

$$
\eta_{i}=\frac{U^{\prime \prime}\left(c_{T}\right)\left(c_{T}+\gamma-y_{i} / \mu\right)}{U^{\prime}\left(c_{T}\right)-U^{\prime}\left(y_{i} / \mu\right)}
$$

From (19) it follows that $y_{L} / \mu<c_{T}<y_{H} / \mu-\gamma$. Thus, $\eta_{H}$ and $\eta_{L}$ are positive and so is the term in braces on the left side of (53). On the right side of (53), the first two terms are negative and the last is positive, so without further restrictions, the sign of the right side of (53) is ambiguous. In our example with three income levels, the densities are $f\left(y_{L}\right)=f\left(y_{H}\right)=0$, so that $(53)$ reduces to

$$
\frac{d c_{T}}{d \mu}=\frac{1}{\mu} \frac{\int_{y_{L}}^{y_{H}} \frac{y}{\mu} f(y) d y}{\left[F\left(y_{L}\right)+1-F\left(y_{H}\right)\right]}>0 .
$$

In our example in which all agents have the same income, the densities are $f\left(y_{L}\right)=\infty$ and $f\left(y_{H}\right)=0$, so that in the limit (53) reduces to $(52)$.

Consider now a third example, in which $y$ is uniform on $[0,1]$ and the utility function is $U(c)=c^{1-\sigma} /(1-\sigma)$ with $\sigma=2$. With these preferences, the cutoff rules $y_{L}\left(c_{T}, \mu\right), y_{H}\left(c_{T}, \mu\right)$ solving (19) are

$$
y_{i}\left(c_{T}, \mu\right)=\mu\left(c_{T}+\gamma / 2 \pm c_{T}\left[\left(1+\frac{\gamma}{2 c_{T}}\right)^{2}-1\right]^{1 / 2}\right)
$$

In this case, the right side of (53) simplifies to $\gamma\left(y_{H}-y_{L}\right) / 2 \mu$, which is positive. Thus, under these restrictions $d c_{T} / d \log \mu$ is positive. 


\section{Appendix B}

Here we solve for the average forward rate and yield curves as functions of the parameters of the moving-average process for money growth. With our money growth process,

$$
\begin{aligned}
& \log \frac{U^{\prime}\left(c_{T t+n}\right)}{P_{t+n}}-\log \frac{U^{\prime}\left(c_{T t}\right)}{P_{t}}= \\
& -\sum_{k=0}^{\infty}\left(\phi\left(\theta_{n+k}-\theta_{k}\right)+\sum_{j=1}^{n} \theta_{j+k}\right) \varepsilon_{t-k}-\sum_{k=0}^{n-1}\left(\phi \theta_{k}+B_{k}\right) \varepsilon_{t+n-k},
\end{aligned}
$$

where $B_{k}=\left(\theta_{0}+\theta_{1}+\ldots+\theta_{k}\right)$. Thus,

$$
E_{t} \log \frac{U^{\prime}\left(c_{T t+n}\right)}{P_{t+n}}-\log \frac{U^{\prime}\left(c_{T t}\right)}{P_{t}}=-\sum_{k=0}^{\infty}\left(\phi\left(\theta_{n+k}-\theta_{k}\right)+\sum_{j=1}^{n} \theta_{j+k}\right) \varepsilon_{t-k}
$$

and

$$
\operatorname{var}_{t}\left(\log \frac{U^{\prime}\left(c_{T t+n}\right)}{P_{t+n}}-\log \frac{U^{\prime}\left(c_{T t}\right)}{P_{t}}\right)=\sum_{k=0}^{n-1}\left(\phi \theta_{k}+B_{k}\right)^{2} \sigma_{\varepsilon}^{2}
$$

Average forward rates and yields are given by

$$
\bar{f}^{n}=\log \bar{\mu}-\log \beta-\left(\phi \theta_{n}+B_{n}\right)^{2} \sigma_{\varepsilon}^{2} / 2
$$

and

$$
\bar{r}^{n}=\log \bar{\mu}-\log \beta-\frac{1}{n} \sum_{k=0}^{n-1}\left(\phi \theta_{k}+B_{k}\right)^{2} \sigma_{\varepsilon}^{2} / 2
$$

Using (40) and letting $A_{n}=\left(\alpha_{0}+\alpha_{1}+\ldots+\alpha_{n}\right)$, we see that average forward rates and yields are given by (48) and (49). 


\section{References}

Alvarez, Fernando, and Andrew Atkeson. (1997) "Money and Exchange Rates in the GrossmanWeiss-Rotemberg Model," Journal of Monetary Economics 40 (no. 3, December): $619-40$.

Backus, David K., Allan W. Gregory, and Stanley E. Zin. (1989) "Risk Premiums in the Term Structure: Evidence from Artificial Economies," Journal of Monetary Economics 24 (no. 3, November): 371-99.

Backus, David K., Allan W. Gregory, and Stanley E. Zin. (1998). "Reverse Engineering the Yield Curve." Manuscript. Stern School of Business, New York University.

Baillie, Richard T. (1996) "Long Memory Processes and Fractional Integration in Econometrics," Journal of Econometrics 73 (no. 1, July): 5-59.

Baumol, William J. (1952) "The Transactions Demand for Cash: An Inventory Theoretic Approach," Quarterly Journal of Economics 66 (November): 545-56.

Campbell, John Y. (1986) "Bond and Stock Returns in a Simple Exchange Model," Quarterly Journal of Economics 101 (no. 4, November): 785-803.

Campbell, John Y., Andrew W. Lo, and A. Craig MacKinlay. (1997) The Econometrics of Financial Markets. Princeton, N. J.: Princeton University Press.

Campbell, John Y., and N. Gregory Mankiw. (1987) "Are Output Fluctuations Transitory?" Quarterly Journal of Economics 102 (no. 4, November): 857-80.

Chari, V.V., Lawrence J. Christiano, and Martin Eichenbaum. (1995) "Inside Money, Outside Money, and Short-Term Interest Rates," Journal of Money, Credit, and Banking 27 (no. 4, Part 2, November): 1354-86.

Chatterjee, Satyajit, and Dean Corbae. (1992) "Endogenous Market Participation and the 
General Equilibrium Value of Money," Journal of Political Economy 100 (no. 3, June): $615-46$.

Christiano, Lawrence J., and Martin Eichenbaum. (1995) "Liquidity Effects, Monetary Policy, and the Business Cycle," Journal of Money, Credit, and Banking 27 (no. 4, Part 1, November): 1113-36.

Cochrane, John H. (1988) "How Big Is the Random Walk in GNP?" Journal of Political Economy 96 (no. 5, October): 893-920.

Evans, Charles L., and David A. Marshall. (1997) "Monetary Policy and the Term Structure of Nominal Interest Rates: Evidence and Theory," Research Department Working Paper 97-10, Federal Reserve Bank of Chicago.

Friedman, Milton. (1968) "The Role of Monetary Policy," American Economic Review 58 (no. 1, March): 1-17.

Fuerst, Timothy S. (1992) "Liquidity, Loanable Funds, and Real Activity," Journal of Monetary Economics 29 (no. 1, February): 3-24.

Grossman, Sanford, and Laurence Weiss. (1983) "A Transactions-Based Model of the Monetary Transmission Mechanism," American Economic Review 73 (no. 5, December): $871-80$.

Jovanovic, Boyan. (1982) "Inflation and Welfare in the Steady State," Journal of Political Economy 90 (no. 3, June): 561-77.

Labadie, Pamela. (1994) "The Term Structure of Interest Rates over the Business Cycle," Journal of Economic Dynamics and Control 18 (no. 3-4, May-July): 671-97.

Lucas, Robert E., Jr. (1990) "Liquidity and Interest Rates," Journal of Economic Theory 50 (no. 2, April): 237-64. 
Romer, David. (1986) "A Simple General Equilibrium Version of the Baumol-Tobin Model," Quarterly Journal of Economics 101 (no. 4, November): 663-85.

Rotemberg, Julio J. (1984) "A Monetary Equilibrium Model with Transactions Costs," Journal of Political Economy 92 (no. 1, February): 40-58.

Tobin, James. (1956) "The Interest-Elasticity of the Transactions Demand for Cash," Review of Economics and Statistics 38 (no. 3, August): 241-47.

Zin, Stanley E. (1998) "Comment on Evans and Marshall," Carnegie-Rochester Conference Series on Public Policy, forthcoming. 
Figure 1: The Cutoff Rule for Trade

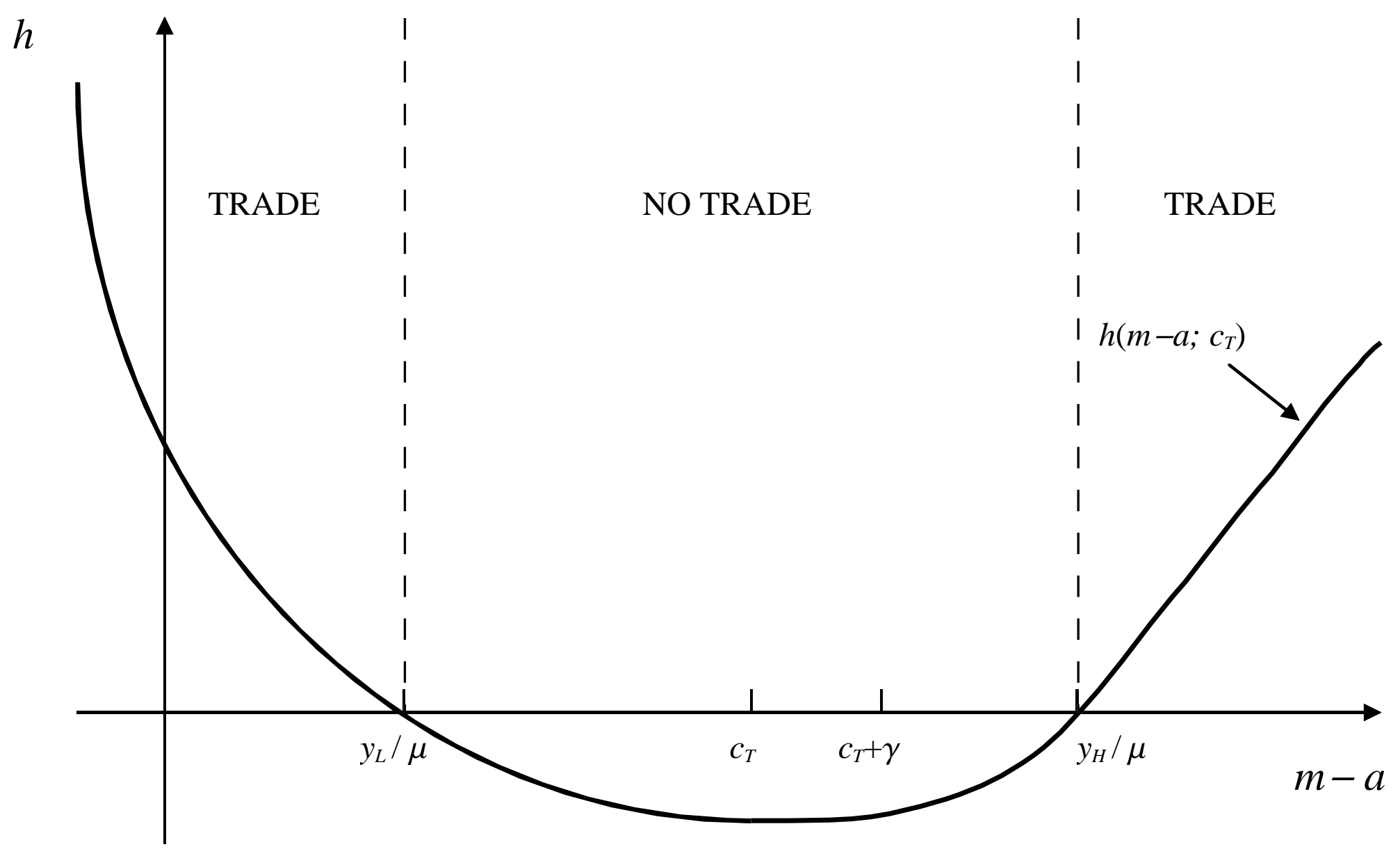

